\title{
Radiation-induced alterations of histone post-translational modification levels in lymphoblastoid cell lines
}

\author{
Belinda Maroschik, Anne Gürtler ${ }^{1,2}$, Anne Krämer , Ute Rößler², Maria Gomolka², Sabine Hornhardt², \\ Simone Mörtl ${ }^{3}$ and Anna A Friedl ${ }^{1,4^{*}}$
}

\begin{abstract}
Background: Radiation-induced alterations in posttranslational histone modifications (PTMs) may affect the cellular response to radiation damage in the DNA. If not reverted appropriately, altered PTM patterns may cause long-term alterations in gene expression regulation and thus lead to cancer. It is therefore important to characterize radiation-induced alterations in PTM patterns and the factors affecting them.

Methods: A lymphoblastoid cell line established from a normal donor was used to screen for alterations in methylation levels at H3K4, H3K9, H3K27, and H4K20, as well as acetylation at H3K9, H3K56, H4K5, and H4K16, by quantitative Western Blot analysis at 15 min, 1 h and $24 \mathrm{~h}$ after irradiation with 2 Gy and 10 Gy. The variability of alterations in acetylation marks was in addition investigated in a panel of lymphoblastoid cell lines with differing radiosensitivity established from lung cancer patients.

Results: The screening procedure demonstrated consistent hypomethylation at H3K4me3 and hypoacetylation at all acetylation marks tested. In the panel of lymphoblastoid cell lines, however, a high degree of inter-individual variability became apparent. Radiosensitive cell lines showed more pronounced and longer lasting H4K16 hypoacetylation than radioresistant lines, which correlates with higher levels of residual $\mathrm{y}-\mathrm{H} 2 \mathrm{AX}$ foci after $24 \mathrm{~h}$.

Conclusion: So far, the factors affecting extent and duration of radiation-induced histone alterations are poorly defined. The present work hints at a high degree of inter-individual variability and a potential correlation of DNA damage repair capacity and alterations in PTM levels.
\end{abstract}

Keywords: Histone modification, Chromatin, Individual radiosensitivity

\section{Background}

It is becoming increasingly evident that the cellular response towards DNA damage is affected by the structure of the chromatin region surrounding the damage site [1], while at the same time the chromatin structure is affected by the damage response [2]. DNA double-strand breaks (DSBs) elicit a response in an Mbp-large chromatin region surrounding the break that involves alterations in several

\footnotetext{
* Correspondence: anna.fried|@|rz.uni-muenchen.de

'Department of Radiation Oncology, Ludwig-Maximilians-University, Munich, Germany

${ }^{4}$ Clinical Cooperation Group "Personalized Radiotherapy in Head and Neck Cancer", Research Unit of Radiation Cytogenetics, Helmholtz Zentrum München, German Research Center for Environment and Health, Neuherberg, Germany

Full list of author information is available at the end of the article
}

post-translational modifications (PTMs). Phosphorylation of histone variant $\mathrm{H} 2 \mathrm{AX}$ at serine 139 (S139) to yield $\gamma-\mathrm{H} 2 \mathrm{AX}$ is a hallmark step in the cellular response to DSB. The $\gamma-\mathrm{H} 2 \mathrm{AX}$ chromatin domains, which can be visualized as ionizing radiation induced foci (IRIF), delineate regions where a large variety of signalling and repair proteins accumulate [3].

Immunofluorescence detection of PTMs demonstrated alterations in several modifications in the $\gamma$-H2AX domain following DSB induction that are associated with regulation of chromatin accessibility, recruitment of DNA damage response factors, and regulation of DNA metabolism and transcription [4]. In some instances, the PTM alterations can also be detected on a more global, i.e. nucleus-wide, manner, e.g. by Western Blot analysis or by analysis of pan-nuclear 
immunofluorescence staining. Tjeertes et al. [5] conducted in U2OS cells a screen for PTMs that alter both after $24 \mathrm{~h}$ incubation with hydroxyurea (a drug that inhibits replication by decreasing the production of desoxyribonucleotides) and $2 \mathrm{~h}$ incubation with phleomycin (a drug that induces strand breaks). Only PTMs that exhibited a drastic intensity change in Western Blot-based analysis were considered further, thus raising the possibility that DSB-specific PTMs or PTMs that exhibit only a small alteration were neglected. We decided to conduct a screen to identify PTMs that specifically alter in response to irradiation. In our screen, we used an immortalized normal human lymphoblastoid cell line (LCL). Cells were irradiated with different doses (0 Gy, 2 Gy, $10 \mathrm{~Gy}$ ) and incubated for $15 \mathrm{~min}, 1 \mathrm{~h}$ and $24 \mathrm{~h}$. Quantitative Western Blot analysis was performed in order to ascertain detection of small alterations. We here report that histone methylation marks exhibit little alteration, except for tri-methylation of H3K4 the levels of which were consistently reduced after irradiation. All acetylation marks tested exhibited a rather longlasting, globally detectable hypoacetylation after irradiation. Histone acetylation marks were also investigated in a panel of LCLs established from lung cancer patients, where we observed a high degree of inter-individual variability. Longterm hypoacetylation of H4K16 was strongest in cell lines exhibiting increased radiosensitivity and enhanced levels of residual $\gamma$-H2AX foci.

\section{Materials and methods}

\section{Tissue culture and irradiation}

Screening experiments were conducted with an EpsteinBarr virus (EBV)-immortalised LCL of a healthy male donor (HuKo). The cells were cultivated in RPMI medium in $75 \mathrm{~cm}^{2}$ flasks $\left(37^{\circ} \mathrm{C}, 5 \% \mathrm{CO}_{2}\right)$ supplemented with $10 \%$ FCS and 1\% penicillin/streptomycin. Irradiation with 2 Gy or $10 \mathrm{~Gy}$ was performed with a ${ }^{137} \mathrm{Cs}$-source (HMW-2000, Markdorf, Germany; dose rate: $0.54 \mathrm{~Gy} / \mathrm{min}$ ) at room temperature. Further experiments were conducted with EBV-immortalised LCLs established from young cancer patients of the LUCY study (LUng Cancer in the Young, www.helmholtz-muenchen/epi/) that differ in radiosensitivity, as tested with Trypan Blue and WST-1 assays (Gürtler et al. 2010). Since the nomenclature of cell lines differs between Gürtler et al. 2010 and the present work, Table 1 lists the names and relative radiosensitivity of the lines used. Line 4008, which was not described in the previous study by Gürtler et al. 2010, exhibits survival characteristics comparable to the sensitive line 36011 (data not shown). All investigations on these cell lines were approved by the Ethics Committee of Bavaria (Germany). An LCL established from an Ataxia teleangiectasia patient (Coriell Institute, NJ, USA: GM03189) and an LCL from the patient's brother with functional ATM (Coriell Institute: GM03323) were used for comparison.
Table 1 Cell lines from LUCY cohort and controls

\begin{tabular}{lll}
\hline $\begin{array}{l}\text { Name in } \\
\text { present work }\end{array}$ & $\begin{array}{l}\text { Name in Gürtler } \\
\text { et al. 2010 }\end{array}$ & $\begin{array}{l}\text { Radiosensitivity } \\
\text { status }\end{array}$ \\
\hline ATM +/+ & $2+$ & Resistant \\
20037 & 3 & Resistant \\
4064 & 9 & Resistant \\
4008 & n.d. & Sensitive \\
4028 & 14 & Sensitive \\
36011 & 6 & Sensitive \\
4060 & 17 & Sensitive \\
ATM -/- & $1-$ & Sensitive \\
\hline
\end{tabular}

\section{Preparation of protein extracts}

Cells were incubated after irradiation for $15 \mathrm{~min}, 1 \mathrm{~h}$ or $24 \mathrm{~h}$ at $37^{\circ} \mathrm{C}, 5 \% \mathrm{CO}_{2}$ and then collected by centrifugation (5 min, $800 \mathrm{rpm}$ ). After washing the cells twice with ice cold PBS the proteins were extracted with RIPA-buffer (150 mM NaCl, 1\% NP-40, $10 \mathrm{mM} \mathrm{MDOC,} \mathrm{0.1 \%} \mathrm{SDS,}$ $50 \mathrm{mM}$ Tris $\mathrm{pH}$ 8.0) on ice. After denaturation for $10 \mathrm{~min}$ at $100^{\circ} \mathrm{C}$ the DNA was removed after one freeze-and-thaw cycle by centrifugation (90 sec, $15000 \mathrm{rpm}$ ).

\section{Immunoblotting and quantitative Western analysis}

The proteins were separated with Laemmli loading dye on $10 \%$ Bis-Tris NuPAGE-gels (Invitrogen) or $12 \%$ TGXPrecast Gels (BioRad). After immunoblotting, membranes were cut in halves, blocked with Roti-Block (Roth) or milk (depending on the antibody (see Table 2)) and incubated

Table 2 Antibodies used in this study

\begin{tabular}{lllll}
\hline Antibody & Company & Order nr. & Dilution & Blocking solution \\
\hline Y-H2AX & millipore & $05-636$ & $1: 1000$ & Roti-Block \\
H3K4 unmodified & millipore & $05-1341$ & $1: 1000$ & Roti-Block \\
H3K4me1 & abcam & ab8895 & $1: 1000$ & Roti-Block \\
H3K4me2 & abcam & ab32356 & $1: 1000$ & Roti-Block \\
H3K4me3 & abcam & ab12209 & $1: 1000$ & Roti-Block \\
H3K9ac & millipore & $06-942$ & $1: 1000$ & Roti-Block \\
H3K9me1 & millipore & $07-450$ & $1: 1000$ & Roti-Block \\
H3K9me2 & millipore & $04-768$ & $1: 1000$ & Roti-Block \\
H3K9me3 & millipore & $07-442$ & $1: 1000$ & Roti-Block \\
H3K27me3 & millipore & $07-449$ & $1: 4000$ & Roti-Block \\
H3K56ac & millipore & $07-677$ & $1: 1000$ & Roti-Block \\
H4K5ac & upstate & $06-759$ & $1: 1000$ & Roti-Block \\
H4K16ac & millipore & $07-329$ & $1: 4000$ & 5\% milk \\
H4K2Ome1 & millipore & $07-1570$ & $1: 1000$ & Roti-Block \\
H4K20me2 & millipore & $07-367$ & $1: 1000$ & Roti-Block \\
H4K20me3 & abcam & ab9053 & $1: 1000$ & Roti-Block \\
\hline & & & & \\
& & &
\end{tabular}


with primary antibodies in the indicated blocking solution before detection with appropriate secondary antibodies m-HRP and r-HRP (Santa Cruz; sc2004 and sc2005, respectively). Blots were developed with Amersham ACL Advance (GE Healthcare). Chemiluminescence was detected and images were acquired with a CHEMISMART documentation system (Peqlab, Vilber Lourmat) and the Chemi-Capt 5000 software. Quantitative analysis was performed with the Bio-1D software (Vilber Lourmat). In order to ascertain detection of small differences between samples, blots were only evaluated when in all lanes to be compared directly equal amounts of protein extracts had been loaded. This was determined by equal intensity of the Tubulin alpha signals (max. 20\% variation over all lanes to be compared). The signals were normalized with respect to the unirradiated samples at each time point and the Tubulin alpha signals. Data are from at least 2 independent experiments. Significance of deviation from controls was determined by t-tests.

All antibodies were tested for specificity by peptide competition assays, except for H3K56ac, for which no competing peptide was commercially available. We could exclude, however, that our antibody directed against $\mathrm{H} 3 \mathrm{~K} 56 \mathrm{ac}$ recognizes $\mathrm{H} 3 \mathrm{~K} 9 \mathrm{ac}$, which has a similar target site (Drogaris et al. 2012). All the tested antibodies were specific except for the antibodies detecting the different H4K20 methylation levels, which exhibited some crossreactivity against the different methylation states.

\section{Quantitative analysis of $\mathrm{Y}-\mathrm{H} 2 \mathrm{AX}$ foci}

DNA damage-induced phosphorylation of the histone H2AX variant was analyzed $24 \mathrm{~h}$ after irradiation with 10 Gy gamma rays. Prior to fixation, cells were spun onto slides for $5 \mathrm{~min}$ at $500 \mathrm{rpm}$ using a Cytospin centrifuge. Cells were fixed in 2\% PFA/PBS for 15 min, permeabilised in $0.25 \%$ Triton $\mathrm{X}-100 / \mathrm{PBS}$ for $5 \mathrm{~min}$, washed three times for 5 min each in PBS and blocked with 1\% BSA/PBS three times for $10 \mathrm{~min}$ each. Cells were covered with $75 \mu \mathrm{l}$ of the primary antibody (anti-phospho-Histone H2A.X(Ser139), \#05-636, Millipore) diluted 1:200 in 1\% BSA/PBS and incubated in a humid chamber at $4^{\circ} \mathrm{C}$ over night. After washing with PBS (5 min), 0,25\% Triton/PBS (10 min), PBS (5 min) and $1 \% \mathrm{BSA} / \mathrm{PBS}$ (7 min), cells were incubated with $75 \mu \mathrm{l}$ of the secondary antibody (Alexa Fluor 555 goat anti mouse; A-21422, Life Technologies) diluted 1:1000 in 1\% BSA/PBS for $45 \mathrm{~min}$ at $4^{\circ} \mathrm{C}$. Again, cells were washed in $0.25 \%$ Triton/PBS two times for $5 \mathrm{~min}$ and in PBS two times for $10 \mathrm{~min}$. For counterstaining, cells were incubated with Hoechst-33342 (Sigma-Aldrich) for $2 \mathrm{~min}$ and washed in PBS two times. Prior to microscopic analysis, cells were covered with $16 \mu \mathrm{l}$ Vectashield (Vector Laboratories) and sealed with a coverslip. For foci analysis, an automated scanning and analysis system (Axioplan 2; Carl Zeiss Jena; Metafer4, MetaSystems) was used [6].

\section{Results and discussion}

We screened for alterations in histone modifications detectable by Western Blot analysis of nuclear extracts from a normal LCL (HuKo) after irradiation with two different doses (2 Gy, 10 Gy) and post-irradiation incubation for three different time periods (15 $\mathrm{min}, 1 \mathrm{~h}, 24 \mathrm{~h})$. The amount of several of the PTMs tested is known to locally alter within the $\gamma-\mathrm{H} 2 \mathrm{AX}$ domain in response to irradiation. Estimating conservatively that $10 \mathrm{~Gy}$ of $\gamma$-irradiation induce about $400 \mathrm{DSB}$, each resulting in a $\gamma-\mathrm{H} 2 \mathrm{AX}$ domain of about $2 \mathrm{Mbp}$ [7], a complete loss of a given PTM within these domains would result in a reduction of the total nuclear signal by about $13 \%$ (assuming homogeneous distribution of the PTM within the $6 \times 10^{9} \mathrm{bp}$ of the genome). We assume that alterations detectable after 10 Gy may be explained by local events, although more global events cannot be excluded. Alterations detectable after 2 Gy, however, most probably involve some global response reactions.

H4K20 methylation is involved in chromatin compaction and DNA damage response (recent review by [8]). While H4K20me3 is a marker for silenced heterochromatin, H4K20me2 (which is present on $80 \%$ of all chromatinbound H4 molecules in proliferating cells) and H4K20me1 are broadly distributed. H4K20me1 and H4K20me2 play important roles in the DNA damage response as binding sites for 53BP1 [9-14]. Nevertheless, bulk levels of H4K20me1 and H4K20me2, as well as H4K20me3, appear to be quite stable after damage induction $[9,11,15,16]$, although others reported increased mono- and dimethylation [17]. In our study, no significant alterations were detectable in the nuclear amount of H4K20me1, H4K20me2 or H4K20me3 (Figure 1).

H3K9 methylation is involved in transcriptional silencing, formation of heterochromatin regions and DNA methylation. Although H3K9me3 has been implicated in the DNA damage response as a binding site for the histone acetyltransferase TIP60 [18], in many studies alterations in the amount of H3K9me3 or H3K9me2 could not be detected, neither within the $\gamma$-H2AX domain nor on a global level ([15,18-23]). Others, however, observed a transient reduction in nuclear H3K9me3 and H3K9me2 immunofluorescence signals within the first 45 min after irradiation with 2 Gy [24]. Our observations on H3K9me3 are compatible with a transient reduction, although statistical significance was only obtained for the sample irradiated with 2 Gy and incubated for $1 \mathrm{~h}$ (Figure 2). Of note, the same antibody was used in our study and the work by Young et al. [24] to detect $\mathrm{H} 3 \mathrm{~K} 9 \mathrm{me} 3$. We could not confirm a reduction in the amount of H3K9me2, however. In addition, we did not observe significant alterations in the amount of H3K9me1 (Figure 2).

H3K27me3 is a histone modification associated with gene silencing via polycomb repressive complex 2 (PRC2) (reviewed by [25]). Recruitment of members of the PRC2 


\section{A}

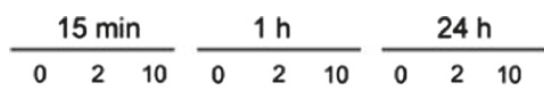

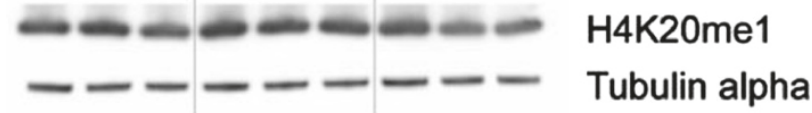

$=-\infty=-\infty$ H4K20me2

------ Tubulin alpha

ED $=5$ H4K20me3

------ Tubulin alpha

B
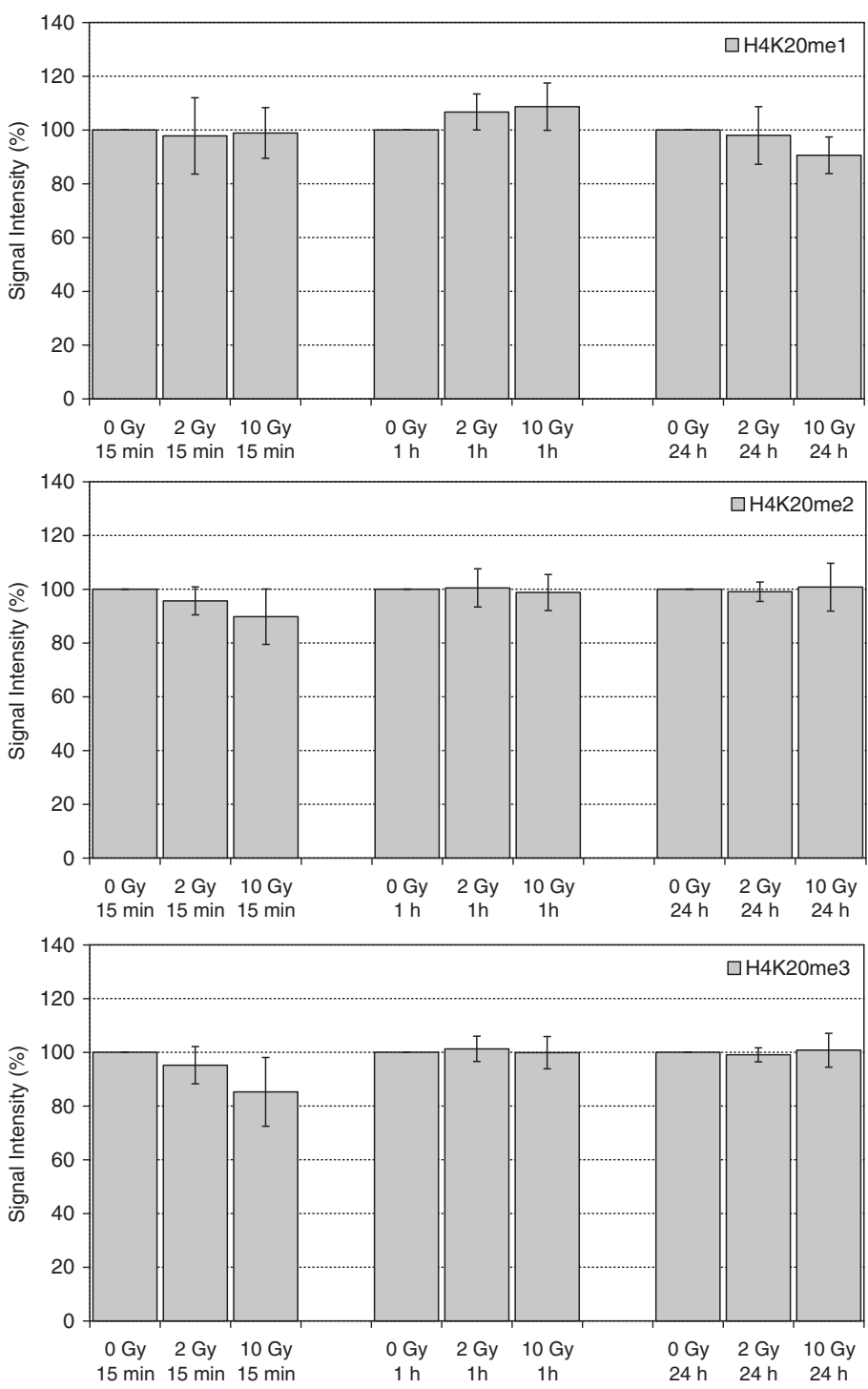

Figure 1 Levels of H4K2Ome1, H4K2Ome2 and H4K20me3 in extracts of HuKo LCLs after irradiation with 0 Gy, 2 Gy and 10 Gy and incubation for $15 \mathrm{~min}, 1 \mathrm{~h}$ and $\mathbf{2 4} \mathrm{h}$. A) representative Western Blot, Tubulin alpha served as loading control. B) Quantitative evaluation, each normalized to unirradiated controls. Indicated are mean and standard error of the mean from 2-3 independent experiments and 1-2 blots per experiment. 


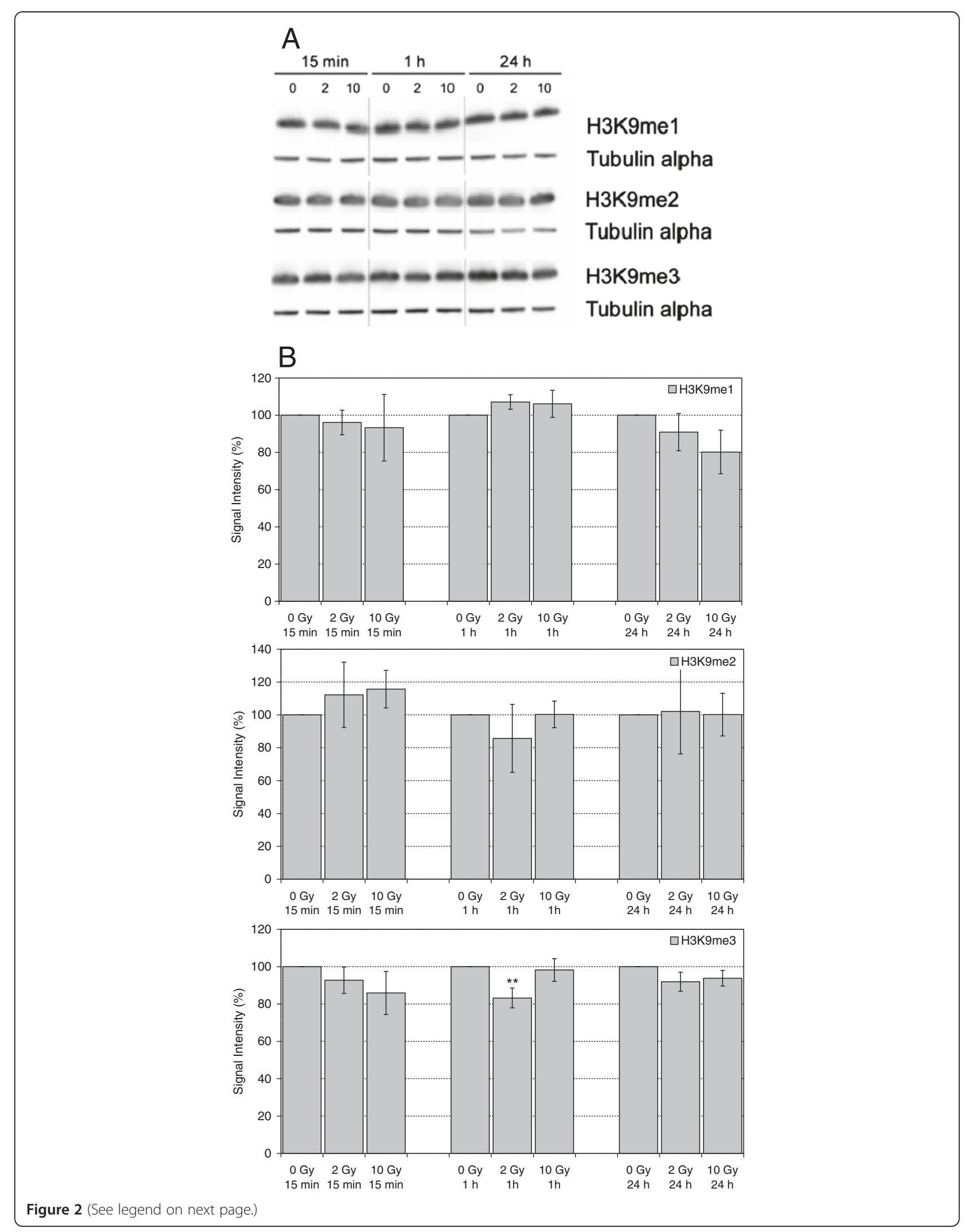


(See figure on previous page.)

Figure 2 Levels of H3K9me1, H3K9me2 and H3K9me3 in extracts of HuKo LCLs after irradiation with 0 Gy, 2 Gy and 10 Gy and incubation for $15 \mathrm{~min}, \mathbf{1}$ h and $24 \mathrm{~h}$. A) representative Western Blot, Tubulin alpha served as loading control. B) Quantitative evaluation, each normalized to unirradiated controls. Indicated are mean and standard error of the mean from 2-3 independent experiments and 1-3 blots per experiment. ${ }^{* *}$ statistically significant with $0.005>a>0.0005$.

complex and accumulation of H3K27me3 has been shown at DNA damage sites induced by laser irradiation or ionizing irradiation $[22,26]$. However, there is no evidence of global alterations in H3K27me3 levels after irradiation (Figure 3).

Methylation at H3K4 is associated with transcriptionally active regions, with $\mathrm{H} 3 \mathrm{~K} 4 \mathrm{me} 3$ preferentially found in $5^{\prime}$ upstream regions of genes. Recently we demonstrated by immunofluorescence analysis a loss of H3K4me3 and H3K4me2 signals in $\gamma$-H2AX domains, which started within minutes after damage infliction by irradiation and increased over time [24]. In addition to local loss of H3K4me3, we also detected a global reduction of H3K4me3 levels by Western blot analysis in HeLa cells [24]. In the present work, a robust reduction of H3K4me3 levels was found in LCL cells under various dose and incubation time combinations (Figure 4), thus corroborating our earlier observations. Mono- and di-methylated H3K4 did not exhibit significant alterations in response to irradiation, while analysis of unmethylated $\mathrm{H} 3 \mathrm{~K} 4$ gave inconclusive results: after irradiation with $10 \mathrm{~Gy}$, a transient decrease was evident after $15 \mathrm{~min}$, followed by an increase after $24 \mathrm{~h}$ (Figure 4). Whether this pattern is causally related to the loss of H3K4me3 remains to be elucidated.

Histone acetylation is generally assumed to contribute to chromatin opening. A classic view on DNA damage response assumes that enhancement of accessibility at damage sites is necessary to warrant efficient recruitment of DNA damage response and repair proteins, and that histone acetylation, especially at the $\mathrm{N}$-terminal tail of $\mathrm{H} 4$, plays a fundamental role in conferring enhanced accessibility (e.g., [27-30], $\mathrm{Xu}$ et al. 2010; reviewed by [31]. A more detailed analysis of histone acetylation patterns following DNA damage induction revealed, however, that the processes are more complex. H4K16ac is a well-characterized modification that was experimentally shown to disrupt chromatin compaction in vitro [32,33]. A biphasic regulation of $\mathrm{H} 4 \mathrm{~K} 16 \mathrm{ac}$ was observed at DSB sites, with a rapid loss of acetylated H4K16 that later is followed by an increase in acetylation levels $[16,34,35]$. Since H4K16 acetylation diminishes 53BP1 binding to H4K20me2, rapid loss of the acetyl group after DSB
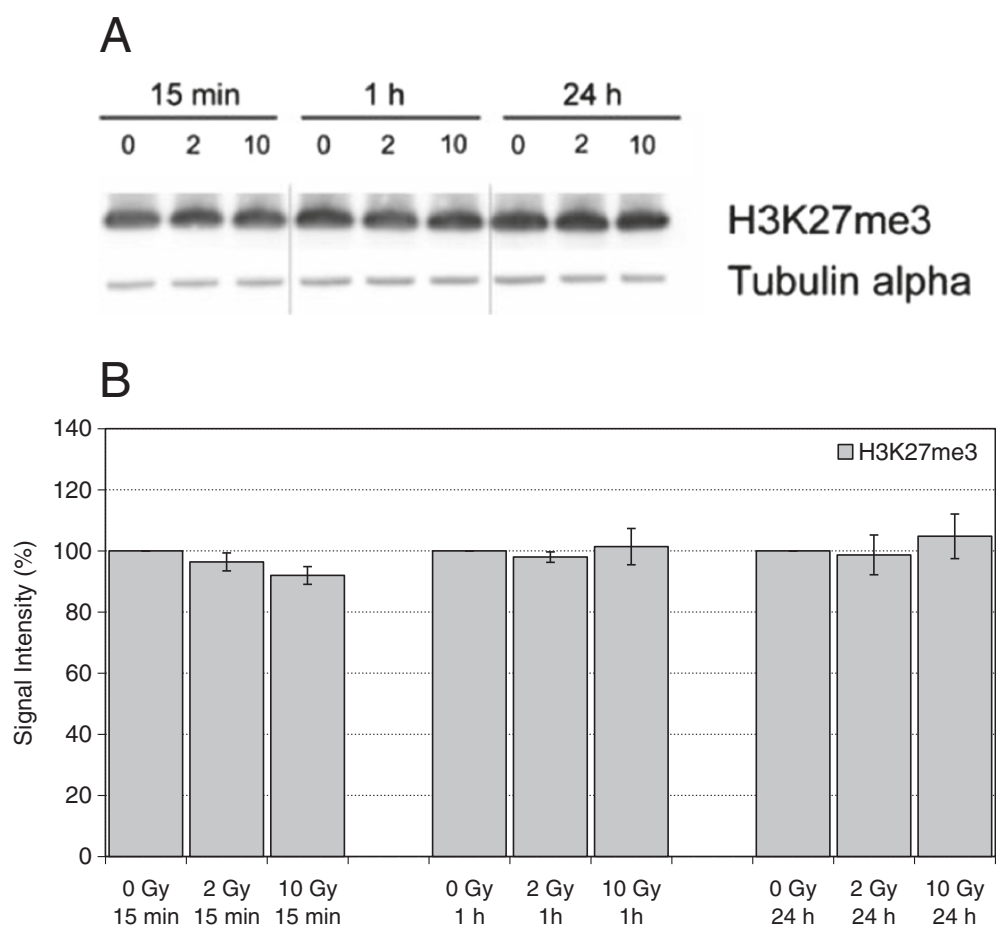

Figure 3 Levels of H3K27me3 in extracts of HuKo LCLs after irradiation with $0 \mathrm{~Gy}, 2 \mathrm{~Gy}$ and $10 \mathrm{~Gy}$ and incubation for $15 \mathrm{~min}, 1 \mathrm{~h}$ and 24 h. A) representative Western Blot, Tubulin alpha served as loading control. B) Quantitative evaluation, each normalized to unirradiated controls. Indicated are mean and standard error of the mean from 2-3 independent experiments and 1-2 blots per experiment. 
Figure 4 Levels of unmodified H3K4, H3K4me1, H3K4me2 and H3K4me3 in extracts of HuKo LCLs after irradiation with $0 \mathrm{~Gy}$, $2 \mathrm{~Gy}$ and $10 \mathrm{~Gy}$ and incubation for $15 \mathrm{~min}, 1 \mathrm{~h}$ and $24 \mathrm{~h}$.

A) representative Western Blot, Tubulin alpha served as loading control. B) Quantitative evaluation, each normalized to unirradiated controls. Indicated are mean and standard error of the mean from 2-3 independent experiments and 1-3 blots per experiment.

** statistically significant with $0.005>a>0.0005,{ }^{* * *}$ statistically significant with $0.0005>a>0.00005$.

induction promotes 53BP1 accumulation at the break site $[16,35]$. On a global level, a similar biphasic dynamics was reported by Hsiao and Mizzen [16] after Bleocin treatment, while others find an increase of H4K16ac levels already very shortly after irradiation [36,37]. In our study, we observe comparable reductions of H4K16ac levels at all time points and doses tested (Figure 5), albeit statistical significance was only obtained for samples irradiated with $2 \mathrm{~Gy}$ and incubated for $15 \mathrm{~min}$ and $24 \mathrm{~h}$.

Globally detectable rapid deacetylation may occur on several N-terminal lysines of H4 [16]. We tested H4K5ac and observe a reduction in the level of this mark at several time points after irradiation, up to $24 \mathrm{~h}$ (Figure 5). Similar patterns were observed with H3K56ac (Figure 5), a modification the biological function of which in mammalian cells is still largely unclear. Conflicting data were reported on global H3K56ac alterations after induction of different damage types $[5,34,38-40]$ and a detailed analysis of global H3K56ac patterns depending on radiation dose and postirradiation incubation had been lacking hitherto. To reconcile conflicting data on whether H3K56ac levels decrease or increase in $\gamma-\mathrm{H} 2 \mathrm{AX}$-decorated chromatin regions $([34,39,41,42])$, a model assuming a biphasic pattern with rapid loss of H3K56ac and subsequent restoration or even overshooting accumulation was proposed, similar to the situation with H4K16ac [34,38]. However, our observations on H4K16ac, H4K5ac, and H3K56ac hint at a long-term reduction in the nuclear amount of these modifications by up to $20-30 \%$, similar after 2 Gy and 10 Gy. Since, according to our earlier estimation, alterations that take place exclusively in the $\gamma-\mathrm{H} 2 \mathrm{AX}$ domain are expected to affect genomic levels by a few percent at most, these observations suggest that not only the immediate vicinity of the DSB sites is concerned.

Another histone acetylation implicated in the DNA damage response is H3K9ac. In addition to a local loss in $\gamma \mathrm{H} 2 \mathrm{AX}$-decorated radiation-induced foci [43], decreased global levels after treatment with various genotoxic agents were reported $[5,44]$. Our data hint at a rapid and transient decrease in H3K9ac levels, the extent of which appears to be lower than observed for the other acetylation sites tested (Figure 5).

To further elucidate the reason for the high preponderance of conflicting reports on alterations in histone PTM 
Figure 5 Levels of H4K16ac, H4K5ac, H3K56ac and H3K9ac in extracts of HuKo LCLs after irradiation with $0 \mathrm{~Gy}, 2 \mathrm{~Gy}$ and $10 \mathrm{~Gy}$ and incubation for $15 \mathrm{~min}, 1 \mathrm{~h}$ and $24 \mathrm{~h}$. A) representative Western Blot, Tubulin alpha served as loading control. B) Quantitative evaluation, each normalized to unirradiated controls. Indicated are mean and standard error of the mean from 2-3 independent experiments and 1-2 blots per experiment. * statistically significant with $0.05>a>0.005,{ }^{* *}$ statistically significant with $0.005>a>0.0005,{ }^{* * *}$ statistically significant with $0.0005>a>0.00005$.

patterns after DSB induction, and to determine whether the observed differences may be associated with different radiosensitivity, we expanded our analysis to a panel of LCL lines established from young lung cancer patients (LUCY cohort; [45]). In prior work radiation sensitivity of these LCLs was established using viability assays (Gürtler et al. 2010). We consider the lines 20037 and 4064 as relatively resistant, with viability levels similar to the ATM-proficient cell line GM03323, which was included as a control. In contrast, the sensitive lines 4008, 4028, 36011, and 4060 exhibit survival levels comparable to the ATM-deficient cell line GM03189. As compared to the resistant lines, all sensitive lines exhibit higher levels of residual $\gamma-\mathrm{H} 2 \mathrm{AX}$ foci at $24 \mathrm{~h}$ after irradiation with $10 \mathrm{~Gy}$, hinting at compromised DSB repair in these lines (Table 3). We investigated H3K56ac, H4K5ac and H4K16ac in these cells lines as these PTMs yielded rather robust alterations in the screen with HuKo LCLs. Histone acetylation levels were investigated $1 \mathrm{~h}$ and $24 \mathrm{~h}$ after irradiation with 10 Gy (Figure 6). We note a prominent inter-individual variability of quality and quantity of alterations in the acetyl marks tested, which in general seems not to be related to radiation sensitivity, with the exception of residual H4K16 hypoacetylation at $24 \mathrm{~h}$ after irradiation. In all four sensitive cell lines established from lung cancer patients, the extent of hypoacetylation at H4K16 was stronger than in any of the radioresistant lines. With reductions in the range of $20-30 \%$, it is possible that hypoacetylation involves not only the $\gamma-\mathrm{H} 2 \mathrm{AX}$ domains, but additional

Table 3 Residual $\gamma$-H2AX foci $24 \mathrm{~h}$ after $\gamma$-irradiation with $10 \mathrm{~Gy}$

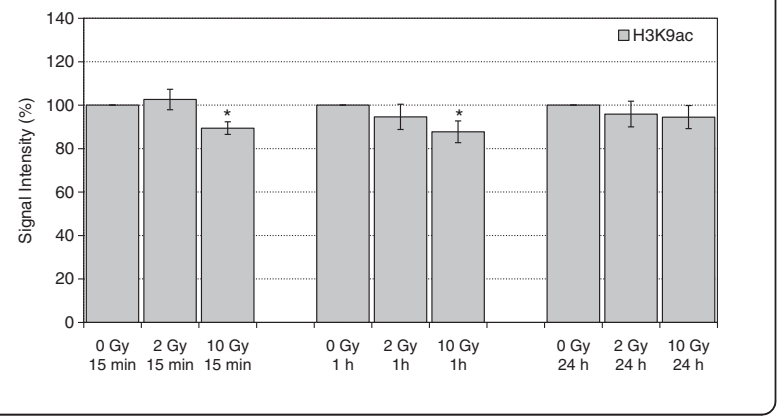

\begin{tabular}{ll}
\hline Cell line & Residual $\boldsymbol{\gamma}$-H2AX foci (compared to unirradiated control) \\
\hline ATM + & $119 \% \pm 5 \%$ \\
20037 & $101 \% \pm 5 \%$ \\
4064 & $99 \% \pm 8 \%$ \\
4008 & $172 \% \pm 4 \%$ \\
4028 & $169 \% \pm 9 \%$ \\
36011 & $167 \% \pm 9 \%$ \\
4060 & $177 \% \pm 11 \%$ \\
ATM - & $141 \% \pm 4 \%$ \\
\hline
\end{tabular}

Shown the mean and standard deviation of two independent experiments. 


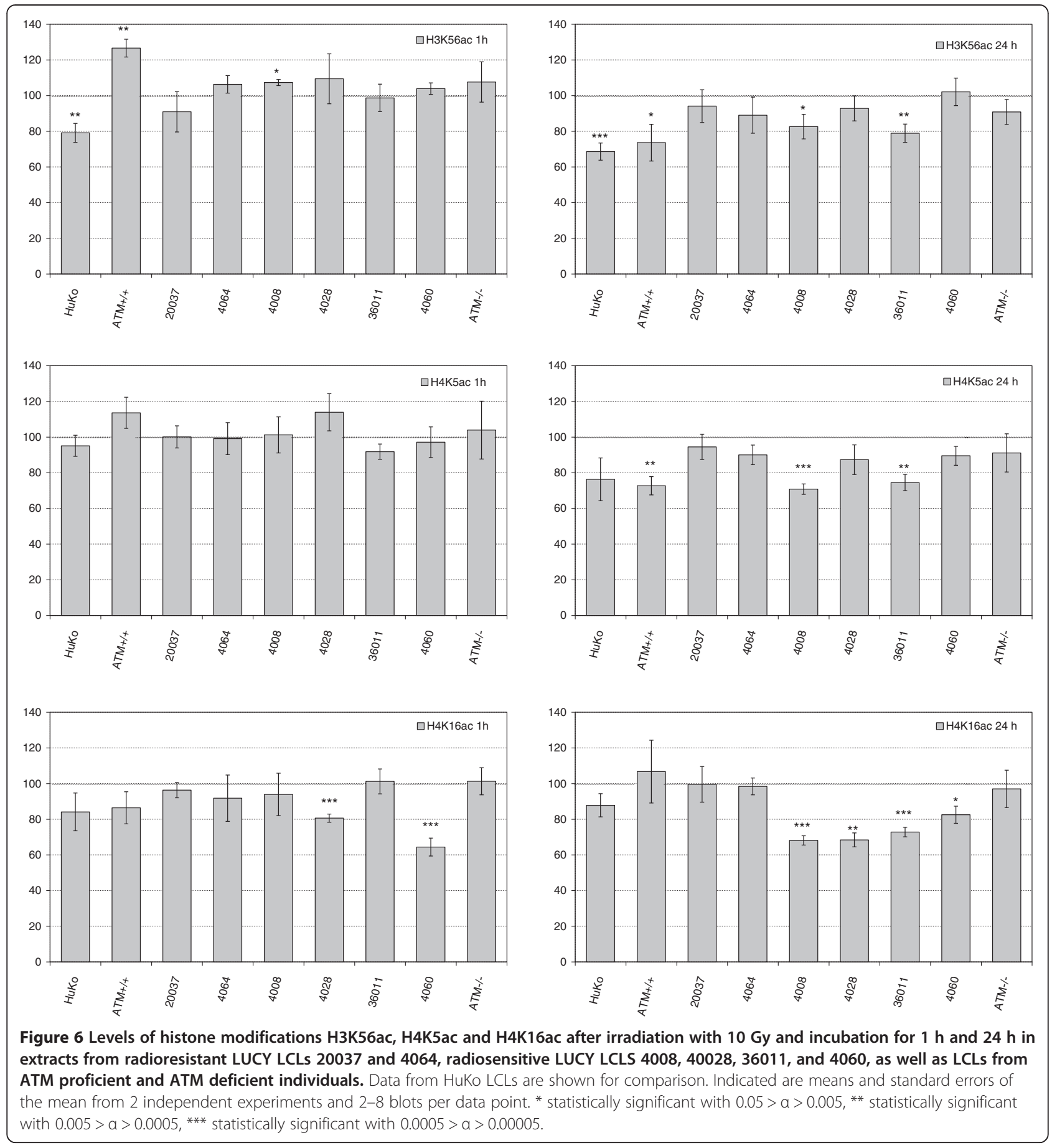

genomic regions. Further experiments are necessary to clarify this question.

While our sample size is too small to allow final conclusions, a correlation between prolonged H4K16 hypoacetylation and radiosensitivity or reduced DSB repair would be intriguing. It is possible that reduced repair retards re-establishment of chromatin structure, therefore protracting hypoacetylation. On the other hand, it is also conceivable that reduced repair is causally linked to prolonged hypoacetylation of H4K16: recent work showed that hypoacetylation at H4K16 results in enhanced binding of 53BP1 and thus reduced binding of Brca1. The presence of 53BP1 blocks resection and thus facilitates DSB repair via non-homologous end joining, while the presence of Brcal would promote resection and repair via homologous recombination $[16,34,35]$. The outcome of prolonged H4K16 hypoacetylation thus may resemble the phenotype of Brca1 deficiency or TIP60 deficiency, i.e. reduced repair 
via homologous recombination, more aberration formation, and increased sensitivity to PARP inhibitors $[16,34,35]$. Others have proposed that H4K16 hypoacetylation leads to a general reduction of DSB repair [46-48]. In addition, H4K16 hypoacetylation may lead to transcriptional deregulation $[49,50]$ and thus affect radiosensitivity. H4K16 hypoacetylation has been implicated as a hallmark of cancer [51]. Both class I and class III histone deacetylases (HDACs) can deacetylate H4K16ac [52]. Inhibitors of HDAC are increasingly considered as cancer therapeuticals that have a potential to radiosensitize tumour cells [53]. Our observations suggest, however, that in some situations the inhibition of H4K16 hypoacetylation may render cells more resistant towards the effects or irradiation. Clearly, more research is needed to clarify the relation between radiation response and histone hypoacetylation.

\section{Conclusions}

By screening a variety of histone PTMs for radiationinduced alterations in a normal human LCL, we observed little variation in histone methylation marks, except for tri-methylation of H3K4 the levels of which were reduced after irradiation. In contrast, consistent alterations in all acetylation marks tested suggest a rather long-lasting, globally detectable hypoacetylation. In a panel of LCLs established from lung cancer patients, we observed, however, a high degree of variability with regard to radiation-induced alterations in histone acetylation. Of special interest, longterm hypoacetylation of H4K16 was strongest in cell lines exhibiting increased radiosensitivity and enhanced levels of residual $\gamma-\mathrm{H} 2 \mathrm{AX}$ foci. This observation may have implications for the use of HDAC inhibitors in radiation oncology.

\section{Abbreviations \\ BSA: Bovine serum albumin; DSB: Double-strand break; EBS: Epsein-Barr-Virus; IRIF: Ionizing radiation-induced foci; LCL: Lymphoblastoid cell line; LUCY: Lung cancer in the young; PBS: Phosphate-buffered saline; \\ PRC2: Polycomb repressive complex 2; PTM: Post-translational modification.}

\section{Competing interests}

The authors declare no competing interests.

\section{Author's information}

Belinda Maroschik is née Mazurek.

\section{Authors' contributions}

AAF and BM designed screening study. BM performed analysis of histone modifications, AG cultivated LCLs and, together with AK, performed radiosensitivity analyses, $\mathrm{AK}$ and UR performed $\mathrm{YH} 2 \mathrm{AX}$ foci analysis. All authors designed characterization of LUCY cell lines. MG and SH provided materials. AAF wrote the manuscript with contributions of BM and SM. All authors read and approved the final manuscript.

\section{Acknowledgement}

This work was financially supported by Federal Ministry of Education and Research (Germany), Kompetenzverbund Strahlenforschung (03NUK007C).

\section{Author details}

'Department of Radiation Oncology, Ludwig-Maximilians-University, Munich, Germany. ${ }^{2}$ Department Radiation Protection and Health, Federal Office for Radiation Protection, Neuherberg, Germany. ${ }^{3}$ Institute of Radiation Biology,
Helmholtz Zentrum München, German Research Center for Environment and Health, Neuherberg, Germany. ${ }^{4}$ Clinical Cooperation Group "Personalized Radiotherapy in Head and Neck Cancer", Research Unit of Radiation Cytogenetics, Helmholtz Zentrum München, German Research Center for Environment and Health, Neuherberg, Germany.

Received: 16 November 2013 Accepted: 23 December 2013 Published: 9 January 2014

\section{References}

1. Murray JM, Stiff T, Jeggo PA: DNA double-strand break repair within heterochromatic regions. Biochem Soc Trans 2012, 40:173-178.

2. Smeenk $G$, van Attikum $H$ : The chromatin response to DNA breaks: leaving a mark on genome integrity. Annu Rev Biochem 2013, 82:55-80.

3. Thompson LH: Recognition, signaling, and repair of DNA double-strand breaks produced by ionizing radiation in mammalian cells: the molecular choreography. Mutat Res 2012, 751:158-246.

4. Friedl AA, Mazurek B, Seiler DM: Radiation-induced alterations in histone modification patterns and their potential impact on short-term radiation effects. Front Oncol 2012, 2:117.

5. Tjeertes JV, Miller KM, Jackson SP: Screen for DNA-damage-responsive histone modifications identifies H3K9Ac and H3K56Ac in human cells. EMBO J 2009, 28:1878-1889.

6. Bannik K, Rössler U, Faus-Kessler T, Gomolka M, Hornhardt S, Dalke C, Klymenko O, Rosemann M, Trott KR, Atkinson M, Kulka U, Graw J: Are mouse lens epithelial cells more sensitive to $\gamma$-irradiation than lymphocytes? Radiat Environ Biophys 2013, 52:279-286.

7. Savic V: Do chromatin changes around a nascent double strand DNA break spread spherically into linearly non-adjacent chromatin? Front Genet 2013, 4:139.

8. Jørgensen S, Schotta G, Sørensen CS: Histone H4 Lysine 20 methylation: key player in epigenetic regulation of genomic integrity. Nucleic Acids Res 2013, 41:2797-2806.

9. Botuyan MV, Lee J, Ward IM, Kim JE, Thompson JR, Chen J, Mer G: Structural basis for the methylation state-specific recognition of histone H4-K20 by 53BP1 and Crb2 in DNA repair. Cell 2006, 127:1361-1373.

10. Hartlerode AJ, Guan Y, Rajendran A, Ura K, Schotta G, Xie A, Shah JV, Scully $\mathrm{R}$ : Impact of histone $\mathrm{H} 4$ lysine 20 methylation on 53BP1 responses to chromosomal double strand breaks. PLoS One 2012, 7:e49211.

11. Houston SI, McManus KJ, Adams MM, Sims JK, Carpenter PB, Hendzel MJ, Rice JC: Catalytic function of the PR-Set7 histone $\mathrm{H} 4$ lysine 20 monomethyltransferase is essential for mitotic entry and genomic stability. J Biol Chem 2008, 283:19478-19488.

12. Schotta G, Sengupta R, Kubicek S, Malin S, Kauer M, Callén E, Celeste A Pagani M, Opravil S, De La Rosa-Velazquez IA, Espejo A, Bedford MT, Nussenzweig A, Busslinger M, Jenuwein T: A chromatin-wide transition to H4K20 monomethylation impairs genome integrity and programmed DNA rearrangements in the mouse. Genes Dev 2008, 22:2048-2061.

13. Spektor TM, Rice JC: Identification and characterization of posttranslational modification-specific binding proteins in vivo by mammalian tethered catalysis. Proc Natl Acad Sci USA 2009, 106:14808-4813.

14. Yang H, Pesavento JJ, Starnes TW, Cryderman DE, Wallrath LL, Kelleher NL, Mizzen CA: Preferential dimethylation of histone $\mathrm{H} 4$ lysine 20 by Suv4-20. J Biol Chem 2008, 283:12085-12092.

15. Goodarzi AA, Kurka T, Jeggo PA: KAP-1 phosphorylation regulates CHD3 nucleosome remodeling during the DNA double-strand break response. Nat Struct Mol Biol 2011, 18:831-839.

16. Hsiao KY, Mizzen CA: Histone H4 deacetylation facilitates 53BP1 DNA damage signaling and double-strand break repair. J Mol Cell Biol 2013, 5:157-165.

17. Yan Q, Dutt S, Xu R, Graves K, Juszczynski P, Manis JP, Shipp MA: BBAP monoubiquitylates histone $\mathrm{H} 4$ at lysine 91 and selectively modulates the DNA damage response. Mol Cell 2009, 36:110-120.

18. Sun $Y$, Jiang $X, X u Y$, Ayrapetov MK, Moreau LA, Whetstine JR, Price BD: Histone $\mathrm{H} 3$ methylation links DNA damage detection to activation of the tumour suppressor Tip60. Nat Cell Biol 2009, 11:1376-1382.

19. Ayoub N, Jeyasekharan AD, Bernal JA, Venkitaraman AR: HP1-beta mobilization promotes chromatin changes that initiate the DNA damage response. Nature 2008, 453:682-686.

20. Luijsterburg MS, Dinant C, Lans H, Stap J, Wiernasz E, Lagerwerf S, Warmerdam DO, Lindh M, Brink MC, Dobrucki JW, Aten JA, Fousteri MI, 
Jansen G, Dantuma NP, Vermeulen W, Mullenders LH, Houtsmuller AB, Verschure PJ, van Driel R: Heterochromatin protein 1 is recruited to various types of DNA damage. J Cell Biol 2009, 185:577-586.

21. Noon AT, Shibata A, Rief N, Löbrich M, Stewart GS, Jeggo PA, Goodarzi AA: 53BP1-dependent robust localized KAP-1 phosphorylation is essential for heterochromatic DNA double-strand break repair. Nat Cell Biol 2010, 12:177-184.

22. Seiler DM, Rouquette J, Schmid VJ, Strickfaden H, Ottmann C, Drexler GA, Mazurek B, Greubel C, Hable V, Dollinger G, Cremer T, Friedl AA: Double-strand break-induced transcriptional silencing is associated with loss of tri-methylation at H3K4. Chromosome Res 2011, 19:883-899.

23. Zheng $\mathrm{H}$, Chen L, Pledger WJ, Fang J, Chen J: p53 promotes repair of heterochromatin DNA by regulating JMJD2b and SUV39H1 expression. Oncogene 2013. doi: 10.1038/onc.2013.6. [Epub ahead of print].

24. Young LC, MCDonald DW, Hendzel MJ: Kdm4b histone demethylase is a DNA damage response protein and confers a survival advantage following $\gamma$-irradiation. J Biol Chem 2013, 288:21376-21388.

25. Simon JA, Kingston RE: Occupying chromatin: Polycomb mechanisms for getting to genomic targets, stopping transcriptional traffic, and staying put. Mol Cell 2013, 49:808-824.

26. Chou DM, Adamson B, Dephoure NE, Tan X, Nottke AC, Hurov KE, Gygi SP, Colaiácovo MP, Elledge SJ: A chromatin localization screen reveals poly (ADP ribose)-regulated recruitment of the repressive polycomb and NuRD complexes to sites of DNA damage. Proc Natl Acad Sci USA 2010, 107:18475-18480.

27. Downs JA, Allard S, Jobin-Robitaille O, Javaherit A, Auger A, Bouchard N, Kron SJ, Jackson SP, Cote J: Binding of chromatin-modifying activities to phosphorylated histone $\mathrm{H} 2 \mathrm{~A}$ at DNA damage sites. Mol Cell 2004, 16:979-990.

28. Jha S, Shibata E, Dutta A: Human Rvb1/Tip49 Is Required for the Histone Acetyltransferase Activity of Tip60/NuA4 and for the Downregulation of Phosphorylation on H2AX after DNA Damage. Mol Cell Biol 2008, 28:2690-2700

29. Kusch T, Florens L, Macdonald WH, Swanson SK, Glaser RL, Yates JR 3rd, Abmayr SM, Washburn MP, Workman JL: Acetylation by Tip60 is required for selective histone variant exchange at DNA lesions. Science 2004, 306:2084-2087.

30. Murr R, Vaissiere T, Sawan C, Shukla V, Herceg Z: Orchestration of chromatinbased processes: min the TRRAP. Oncogene 2007, 26:5358-5372.

31. Xu Y, Price BD: Chromatin dynamics and the repair of DNA double strand breaks. Cell Cycle 2011, 10:261-267.

32. Robinson PJ, An W, Routh A, Martino F, Chapman L, Roeder RG, Rhodes D: $30 \mathrm{~nm}$ chromatin fibre decompaction requires both $\mathrm{H} 4-\mathrm{K} 16$ acetylation and linker histone eviction. J Mol Biol 2008, 381:816-825.

33. Shogren-Knaak M, Peterson CL: Switching on chromatin: mechanistic role of histone H4-K16 acetylation. Cell Cycle 2006, 5:1361-1365.

34. Miller KM, Tjeertes JV, Coates J, Legube G, Polo SE, Britton S, Jackson SP: Human HDAC1 and HDAC2 function in the DNA-damage response to promote DNA nonhomologous end-joining. Nat Struct Mol Biol 2010 17:1144-1151

35. Tang J, Cho NW, Cui G, Manion EM, Shanbhag NM, Botuyan MV, Mer G, Greenberg RA: Acetylation limits 53BP1 association with damaged chromatin to promote homologous recombination. Nat Struct Mol Biol 2013, 20:317-325.

36. Gupta A, Sharma GG, Young CS, Agarwal M, Smith ER, Paull TT, Lucchesi JC, Khanna KK, Ludwig T, Pandita TK: Involvement of human MOF in ATM function. Mol Cell Biol 2005, 25:5292-5305.

37. Li X, Corsa CA, Pan PW, Wu L, Ferguson D, Yu X, Min J, Dou Y: MOF and H4 K16 acetylation play important roles in DNA damage repair by modulating recruitment of DNA damage repair protein Mdc1. Mol Cell Biol 2010, 30:5335-5347.

38. Battu A, Ray A, Wani AA: ASF1A and ATM regulate H3K56-mediated cell-cycle checkpoint recovery in response to UV irradiation. Nucleic Acids Res 2011, 39:7931-7945.

39. Das C, Lucia MS, Hansen KC, Tyler JK: CBP/p300-mediated acetylation of histone $\mathrm{H} 3$ on lysine 56 . Nature 2009, 459:113-117.

40. Kari V, Shchebet A, Neumann H, Johnsen SA: The H2B ubiquitin ligase RNF40 cooperates with SUPT16 $\mathrm{H}$ to induce dynamic changes in chromatin structure during DNA double-strand break repair. Cell Cycle 2011, 10:3495-3504.

41. Vempati RK, Jayani RS, Notani D, Sengupta A, Galande S, Haldar D: p300-mediated acetylation of histone $\mathrm{H} 3$ lysine 56 functions in DNA damage response in mammals. J Biol Chem 2010, 285:28553-28564.
42. Toiber D, Erdel F, Bouazoune K, Silberman DM, Zhong L, Mulligan P, Sebastian C, Cosentino C, Martinez-Pastor B, Giacosa S, D'Urso A, Näär AM Kingston R, Rippe K, Mostoslavsky R: SIRT6 recruits SNF2H to DNA break sites, preventing genomic instability through chromatin remodeling. Mol Cell 2013, 51:454-468.

43. Seiler D: Epigenetic alterations at gamma-H2AX-decorated chromatin regions after ionizing radiation. München: $\mathrm{PhD}$ thesis, Ludwig Maximilians-Universität; 2012.

44. Shimada M, Niida H, Zineldeen DH, Tagami H, Tanaka M, Saito H, Nakanishi $\mathrm{M}$ : Chk1 is a histone $\mathrm{H} 3$ threonine 11 kinase that regulates DNA damage-induced transcriptional repression. Cell 2008, 132:221-232.

45. Schneider J, Illig T, Rosenberger A, Bickeböller H, Wichmann HE: Detection of ATM gene mutations in young lung cancer patients: a population-based control study. Arch Med Res 2008, 39:226-231.

46. Krishnan V, Chow MZ, Wang Z, Zhang L, Liu B, Liu X, Zhou Z: Histone H4 lysine 16 hypoacetylation is associated with defective DNA repair and premature senescence in Zmpste24-deficient mice. Proc Natl Acad SCi USA 2011, 108:12325-12330.

47. Peng L, Ling H, Yuan Z, Fang B, Bloom G, Fukasawa K, Koomen J, Chen J, Lane WS, Seto E: SIRT1 negatively regulates the activities, functions, and protein levels of hMOF and TIP60. Mol Cell Biol 2012, 32:2823-2836.

48. Sharma GG, So S, Gupta A, Kumar R, Cayrou C, Avvakumov N, Bhadra U, Pandita RK, Porteus MH, Chen DJ, Cote J, Pandita TK: MOF and histone H4 acetylation at lysine 16 are critical for DNA damage response and double-strand break repair. Mol Cell Biol 2010, 30:3582-3595.

49. Füllgrabe J, Lynch-Day MA, Heldring N, Li W, Struijk RB, Ma Q, Hermanson O, Rosenfeld MG, Klionsky DJ, Joseph B: The histone H4 lysine 16 acetyltransferase hMOF regulates the outcome of autophagy. Nature 2013, 500:468-471.

50. Horikoshi N, Kumar P, Sharma GG, Chen M, Hunt CR, Westover K, Chowdhury S, Pandita TK: Genome-wide distribution of histone H4 Lysine 16 acetylation sites and their relationship to gene expression. Genome Integr 2013, 4:3.

51. Fraga MF, Ballestar E, Villar-Garea A, Boix-Chornet M, Espada J, Schotta G, Bonaldi T, Haydon C, Ropero S, Petrie K, lyer NG, Pérez-Rosado A, Calvo E, Lopez JA, Cano A, Calasanz MJ, Colomer D, Piris MA, Ahn N, Imhof A, Caldas C, Jenuwein T, Esteller M: Loss of acetylation at Lys 16 and trimethylation at Lys 20 of histone $\mathrm{H} 4$ is a common hallmark of human cancer. Nat Genet 2005, 37:391-400.

52. Gong F, Miller KM: Mammalian DNA repair: HATs and HDACs make their mark through histone acetylation. Mutat Res 2013, 750:23-30.

53. Groselj B, Sharma NL, Hamdy FC, Kerr M, Kiltie AE: Histone deacetylase inhibitors as radiosensitisers: effects on DNA damage signalling and repair. Br J Cancer 2013, 108:748-754.

54. Guertler A, Kraemer A, Roessler U, Hornhardt S, Kulka U, Moertl S, Friedl AA, Illig T, Wichmann E, Gomolka M: The WST survival assay: an easy and reliable method to screen radiation-sensitive individuals. Radiat Prot Dosimetry 2011, 143:487-490.

doi:10.1186/1748-717X-9-15

Cite this article as: Maroschik et al:: Radiation-induced alterations of histone post-translational modification levels in lymphoblastoid cell lines. Radiation Oncology 2014 9:15

\section{Submit your next manuscript to BioMed Central and take full advantage of:}

- Convenient online submission

- Thorough peer review

- No space constraints or color figure charges

- Immediate publication on acceptance

- Inclusion in PubMed, CAS, Scopus and Google Scholar

- Research which is freely available for redistribution 